\title{
EVALUATION OF ANGIOPOIETIN-2 AS AN EARLY MARKER FOR DIABETIC NEPHROPATHY INZAGAZIG UNIVERSITY HOSPITALS
}

\author{
Mohammad Hassan Aly ", Mohammad Abbas Arafat *, Ola Aly Hussein **, HanaaHosny**, and Ayman \\ RiyadhAbdel-Hammed El Sayed MSc*. \\ "Nephrology Unite, Internal Medicine Department, Faculty of Medicine, Zagazig University, Egypt. \\ Clinical and Chemical PathologyDepartment, Faculty of Medicine, Zagazig University, Egypt.
}

\begin{abstract}
- $\quad$ Background: To assess the validity of measuring plasma Angiopoietin as a biomarker for early detection of diabetic nephropathy and todetermine the relation between plasma Ang-2 and inflammation in diabetic nephropathy patients in Zagazig university Hospitals.

- $\quad$ Subjects and methods:This study included a total of 76 diabetic patients divided to microalbuminuria and macroalbuminuria groups, each group contained 38 patients in addition to 40 healthy control subjects.

Results: Plasma levels of Ang-2 was significantly higher in patients with microalbuminuria and macroalbuminuria compared to healthy controls. Indeed, Ang-2 levels steadily increases with the progression of albuminuria . The study showed significant positive correlation between plasma Ang-2, MAP and creatinine, uric acid, phosphorus, CRP, total cholesterol and triglycrides. We observed also significant negative correlation between plasma Ang-2 and Hb, eGFR, serum calcium and albumin.

- Conclusion:Our results indicated that Plasma Angiopoietin-2 levels are elevated in patients with diabetic nephropathy . plasma Ang-2 steadily increase with the progression of albuminuria, suggesting their possible role as early markers of microvascular angiopathy of glomeruli . Plasma Ang-2 is related to CRP, this implies that elevated levels of this biomarker occur as a result of inflammation and vascular dysfunction as a part of atherosclerotic process.

- Abbreviations: Ang-2 =Angiopoietin-2, $\mathbf{C R P}=$ C-reactive protein, $\mathbf{H b}=$ hemoglobin, $\mathbf{A C R}=$ albumin-creatinine ratio, ESRD = end stage renal disease, $\mathbf{M A P}=$ mean arterial pressure, $\mathbf{F B S}=$ fasting blood suger.

Keywords: Angiopoietin; Diabetes mellitus;

Corresponding author:Ayman Riyadh Abdel-Hammed Mobile: 01092192223Email: Ayman.riyadh4@gmail.com.
\end{abstract}

\section{INTRODUCTION}

D iabetic nephropathy (DN) is a major microvascular complication of diabetes mellitus. Proteinuria is present in patients with advanced stage DN. Early detection and intervention in diabetic patients with DN will possibly reverse, or even eliminate, underlying renal damage. Therefore, the early diagnosis and treatment of DN are crucial [1]\&[2].

The most critical issue in clinical nephrology is relentless and progressive increase in the patients with end-stage renal disease (ESRD) in worldwide. The impact of diabetic nephropathy on the increasing population with chronic kidney disease (CKD) and ESRD is enormous. The intensified multifactorial intervention in patients with type 2 diabetes mellitus resulted in reduced risk of microangiopathy, cardiovascular events and mortality in Steno type 2 randomized studies; however, the incidence of ESRD is progressively increasing in worldwide [3].
Albuminuria is one of the manifestations in renal glomerular disease. Moreover, it is also indicative of endothelial damage and vascular disease in diverse populations. Evidence has shown that albuminuria is an independent predictor of cardiovascular events in both CKD and non-CKD patients[4]\&[5]. Moreover, systemic microinflammation also infers the increased cardiovascular morbidity and mortality [6]\&[7]. Although albuminuria and microinflammation explain the complex interplay in $\mathrm{CKD}$, the effectors mediating the cross talk between CKD and CVD are still not confirmative.

Recently, renal microvascular disease and renal ischemia have been demonstrated to correlate indirectly with the development of diabetic kidney disease and its function . Among these are angiogenic and anti-angiogenic factors, angiopoietins and endostatin. With respect to therapeutic prevention, implementation of treatment at early stage of diabetic and 
nondiabetic kidney disease is able to restore renal perfusion and function [8].

Angiopoietin/Tie-2 as growth factor family is thought to be associated with the development of DN [9]. Within the angiopoietin family, angiopoietin-1 (Ang-1) and angiopoietin-2 (Ang-2) are the best-studied ligands for Tie-2 receptors. Ang-1 signalling via Tie-2 is involved in capillary developing, endothelial

\section{SUBJECTS AND METHODS}

This study was carried out at internal medicine and Clinical Pathology departments, Zagazig University Hospitals . A written informed consent were taken from all participants.

Subjects : This study included 76 patients classified to microalbuminuria and macroalbuminuria groups ,38 cases for each group in addition to 40 healthy individuals as control group. All patients were subjected to medical and clinical history taking and full clinical assessment for select patients with diabetic nephropathy. Established type 2 diabetes mellitus (diagnosed according to WHO criteria (i.e., fasting blood glucose (FBG) $\geq 126$ $\mathrm{mg} / \mathrm{dL}$, postprandial blood glucose $\geq 200$ $\mathrm{mg} / \mathrm{dL}$, symptoms of DM with random blood glucose $\geq 200 \mathrm{mg} / \mathrm{dL}$, or $\mathrm{A} 1 \mathrm{C} \geq 6.5 \%$ ), age more than 18 years, under oral anti-diabetic and/or insulin therapy were included in the study. Exclusion criteria were; (1) congestive heart failure, (2) hypertension, (3) peripheral artery disease, (4) critical illness (sepsis and shock), (5) pregnant females, (6) malignancy and (7) current infection.

\section{Sampling and lab investigation:}

After 12 to 14 hour fasting five $\mathrm{ml}$ of venous blood samples were withdrawn and delivered into EDTA and plain vacutainer tubes for Ang-2 determination and measuring of Complete blood count, Kidney function tests, Liver function tests, fasting blood sugar (FBS), HbA1c,serum calcium and phosphorus, serum uric acid, serum total cholesterol, serum triglycerides, urine analysis, CRP. Samples were centrifuged for 15 minutes at $4000 \mathrm{rpm}$ within 30 minutes of collection, plasma was stored at $-20^{\circ} \mathrm{C}$ for Plasma Ang-2 level cell survival, and vascular remodelling [10]. Ang-2 is a naturalantagonist of Ang-1 [10, 11, 12]. Emerging evidence suggests that angiopoietin has critical role in pathogenesis of glomerular disease in DM[13-14]. The aim of this work is to assess the validity of measuring plasma Ang-2 as a biomarker for early detection of diabetic nephropathy

estimation by ELIZA. Urine samples were withdrawn for microalbuminuria, Urine samples were withdrawn for microalbuminuria and calculation of urine albumin creatinine ratio (ACR) and estimated glomerular filtration rate (eGFR ) .

Plasma Ang-2 was assayed by enzymelinked immunoadsorbent assay using Human Angiopoietin $\Pi$ ELISA Kit, Bioneovan Co, Ltd - All routine investigations were done on cobas c 311/501 analyzers, Roche Diagnostics GmbH, D68298 Mannheim-Germany, CRP and microalbuminuria were done by Immunoturbidometric assay . The glomerular filtration rate was calculate by Chronic Kidney Disease Epidemiology Collaboration equation, (Levey et al., 2009).

\section{Statistical analysis}

All data were analyzed using Statistical Package for the Social Sciences (SPSS version 20.0) software for analysis. According to the type of data qualitative represent as number and percentage, quantitative continues group represent by mean $\pm \mathrm{SD}$, the following tests were used to test differences for significance; difference and association of qualitative variable by Chi square test (X2). Differences between parametric quantitative Multiple parametric by ANOVA non parametric by Kruskal Wallis, agreement by Kappa agreement. Post hoc test was done by Tukey post-hoc test. $\mathrm{P}$ value was set at $<0.05$ for significant results $\&<0.001$ for high significant result.

\section{RESULTS}

Demographic information was collected; the enrolled number of the study was 116 participants, among them 50 males and 66 females, with mean age of $56.8 \pm 8.5$ years. 
Table (1): Significant statistical difference among groups as regard Plasma Ang-2 ( $\mathrm{F}=$ 270.7, $\mathrm{p}<0.001)$ and UACR $(\mathrm{F}=28.6$, $\mathrm{p}<0.001)$.

Table (2) : There is significant positive correlation between UACR and MAP, HB, serum creatinine, CRP, uric acid, total cholesterol, triglycerides, micro-albuminuria , there is significant negative correlation between UACR and $\mathrm{Hb}$, serum albumin, eGFR ( $\mathrm{p}<$ $0.05)$. There is no significant correlation between UACR and age, serum total calcium, phosphorus and plasma Ang-2 ( $\mathrm{p}>0.05)$,

Table (3) : showed significant positive correlation between plasma Ang-2 and MAP, CRP, serum creatinine, uric acid, phosphorus, total cholesterol, and triglycerides and there are significant negative correlation between plasma Ang-2 and $\mathrm{Hb}$, eGFR, serum total calcium and albumin $(p>0.05)$. No significant correlation between plasma Ang-2 and age, micro-albuminuria and UACR $(\mathrm{p}>$ $0.05)$,

Table (1): Comparison between the studied groups as regard marker distribution:

\begin{tabular}{|c|c|c|c|c|c|c|}
\hline Parameter & $\begin{array}{l}\text { Control } \\
(n=40)\end{array}$ & $\begin{array}{c}\text { micro } \\
\text { albuminuria } \\
(\mathrm{n}=38)\end{array}$ & $\begin{array}{c}\text { macro } \\
\text { albuminuria } \\
(\mathrm{n}=38)\end{array}$ & P1 & P2 & P3 \\
\hline $\begin{array}{l}\text { UACR } \\
(\mathrm{mg} / \mathrm{g})\end{array}$ & $13.2 \pm 6.1$ & $141 \pm 90.9$ & $\begin{array}{l}2698.7 \\
\pm 224.7 \\
\end{array}$ & 0.001 & 0.001 & 0.001 \\
\hline $\mathrm{CRP}(\mathrm{ml} / \mathrm{gm})$ & $4.8 \pm 0.7$ & $8.8 \pm 2.6$ & $13.6 \pm 9.8$ & 0.207 & .006 & 0.131 \\
\hline Ang-2 (pg/ml) & $\begin{array}{c}51.9 \\
\pm 22.3\end{array}$ & $155.6 \pm 11.8$ & $189.4 \pm 9.5$ & 0.01 & 0.001 & 0.01 \\
\hline
\end{tabular}

UACR :Urine albumin creatinine ratio

Ang-2: Angiopoeitin-2

P1: control vs micro albuminuria , P2 : control vs macro albuminuria , P3: micro albuminuria vs macro albuminuria

Table (2) : Correlation between UACR and other Lab parameters:

\begin{tabular}{lcc}
\hline UACR correlations with & $\mathrm{r}$ & $\mathrm{p}$ \\
\hline Age $($ year) & -0.150 & 0.158 \\
\hline MAP & -0.072 & 0.503 \\
\hline HB $(\mathrm{g} / \mathrm{dl})$ & $-0.301^{* * * *}$ & 0.004 \\
\hline S. Creatinine $(\mathrm{mg} / \mathrm{dl})$ & -0.041 & 0.700 \\
\hline eGFR $(\mathrm{ml} / \mathrm{min} / 1.73 \mathrm{~m} 2)$ & -0.026 & 0.806 \\
\hline Uric acid $(\mathrm{mg} / \mathrm{dl})$ & -0.015 & 0.892 \\
\hline Calcium $(\mathrm{mg} / \mathrm{dl})$ & -0.190 & 0.073 \\
\hline Phosphorus $(\mathrm{mg} / \mathrm{dl})$ & 0.137 & 0.198 \\
\hline CRP $(\mathrm{mg} / \mathrm{l})$ & 0.088 & 0.410 \\
\hline Total cholesterol (mg/dl) & 0.630 & $<0.001$ \\
\hline Triglycrides $(\mathrm{mg} / \mathrm{dl})$ & 0.381 & $<0.001$ \\
\hline S.albumin $(\mathrm{g} / \mathrm{dl})$ & -0.607 & $<0.001$ \\
\hline Microalbuminuria & 0.677 & $<0.001$ \\
\hline Ang_2 (pg/ml) (Mean \pm SD) & 0.182 & 0.086 \\
\hline
\end{tabular}


Table (3): Correlation between plasma Ang-2 and otherLab parameters:

\begin{tabular}{ccc}
\hline $\begin{array}{c}\text { Pl. Ang-2 }(\mathrm{pg} / \mathrm{ml}) \\
\text { correlations with }\end{array}$ & $\mathrm{r}$ & $\mathrm{p}$ \\
\hline Age $(\mathrm{year})$ & 0.122 & 0.253 \\
\hline MAP & 0.696 & $<0.001$ \\
\hline S. Creatinine $(\mathrm{mg} / \mathrm{dl})$ & 0.800 & $<0.001$ \\
\hline eGFR $(\mathrm{ml} / \mathrm{min} / 1.73 \mathrm{~m} 2)$ & -0.708 & $<0.001$ \\
\hline Microalbuminuria & 0.177 & .096 \\
\hline UACR $(\mathrm{mg} / \mathrm{gm})$ & 0.182 & 0.086 \\
\hline Hb $(\mathrm{g} / \mathrm{dl})$ & -0.533 & $<0.001$ \\
\hline Uric acid $(\mathrm{mg} / \mathrm{dl})$ & 0.577 & $<0.001$ \\
\hline Calcium $(\mathrm{mg} / \mathrm{dl})$ & -0.580 & $<0.001$ \\
\hline CRP $($ Mean $\pm \mathrm{SD})$ & 0.214 & .043 \\
\hline Phosphorus $(\mathrm{mg} / \mathrm{dl})$ & 0.551 & $<0.001$ \\
\hline Total cholesterol $(\mathrm{mg} / \mathrm{dl})$ & 0.551 & $<0.001$ \\
\hline Triglycrides $(\mathrm{mg} / \mathrm{dl})$ & 0.715 & $<0.001$ \\
\hline S. albumin $(\mathrm{g} / \mathrm{dl})$ & -0.439 & $<0.001$ \\
\hline
\end{tabular}

MAP: Mean arterial pressure CRP : c -reactive protein $\mathrm{Hb}$ : hemoglobin

\section{DISCUSSION}

Microalbuminuria is an early sign of DN, which correlates with and can predict the progression of renal damage and cardiovascular morbidity, so the discovery of biomarkers for the earlier stages of DN would enable early intervention to reduce the impact of this chronic vascular complication [10].

Recently, renal microvascular disease and renal ischemia have been demonstrated to correlate indirectly with the development of diabetic kidney disease and its function [11], angiogenic and anti-angiogenic factors as angiopoietins and endostatin, with respect to therapeutic prevention, implementation of treatment at early stage of diabetic and nondiabetic kidney disease is able to restore renal perfusion and function [11 ].

Therefore, we conducted this cross-sectional study in the period from March 2015 to March 2016 at Zagazig University Hospitals, Internal Medicine Department and clinical pathology department aiming at assessing the validity of measuring plasma Ang-2 as a biomarker for early detection of diabetic nephropathy.

In the present study, plasma levels of Ang-2 was significantly higher in patients with microalbuminuria and macroalbuminuria compared to healthy controls. Indeed, plasma Ang-2 steadily increases with the progression of albuminuria and renal impairment as shown in table (9). This result was in agreement with Rizkalla et al., (2005) who had studied plasma Ang-1 and Ang-2 level in a rat model of type1 diabetic nephropathy, they found a decrease in renal level of Ang-1 and elevation of plasma Ang-2 at 8 weeks after the induction of diabetes and Ang-2 was observed in glomerular endothelia and podocytes[15].

Also, Chen et al., (2015) found serum levels of Ang-2 were markedly increased in diabetic patients compared with values in the control group $(P<0.001)$. Moreover, serum Ang-2 was significantly higher in patients with macroalbuminuria than those in the normalalbuminuria and microalbuminuria groups $(P<0.001)$. They observed in their study that serum and urinary Ang-2 are increased in normoalbuminuric patients. This observation is likely due to the tubular pathophysiological changes, which occur before the glomerular stage of disease. This suggests that the serum and urinary Ang-2 are related to subclinical tubular impairment and may be an earlier 
measurable marker of renal involvement before the onset of albuminuria[16].

Lim et al., (2004) they founded that plasma Ang-2 (but not Ang-1) was higher in patients with diabetes compared to controls $(p<0.01)$, with no significant difference between patients with and without CVD[17]. This finding goes in harmony with that reported by Lip et al., (2004) as they observed that Plasma VEGF levels ( $p<0.001)$ and plasma Ang-2 levels ( $p$, $<0.001)$ were significantly higher in diabetic patients compared to controls[18].

Possible mechanisms for these findings include hyperglycemia is the dominant pathophysiological hallmark of diabetes, and may exert toxic pathological effects on the endothelium through accelerated formation and accumulation of advanced glycation endproducts (AGE) [19]. The accumulation of AGE can up-regulate Ang-2 mRNA expression [20,21] . [21]. The strong inter correlation reflects the close relationship between these factors, suggesting a tight and preferential control mechanism for angiogenesis and vascular permeability [17].

We observed no significant correlation between plasma Ang-2 and age, but there is significant positive correlation between plasma Ang-2 and MAP, serum creatinine, serum uric acid, serum phosphorus, CRP, serum total cholesterol, serum triglycerides. We observed also significant negative correlation between plasma Ang-2 and $\mathrm{Hb}$, eGFR, serum total calcium and serum albumin as shown in table (9), this agrees with that reported by $\mathbf{L i m}$, et al., (2004) who found no significant relationships of plasma Ang-1 and plasma Ang-2 with age. Plasma Ang-2 correlated strongly, and both correlated significantly with HbA1c[17].

Martynov et al., (2013) also had evaluated alteration on serum concentration of circulating Ang-1 and Ang-2, and their association with markers of renal damage (albuminuria, glomerular filtration rate) and anemia in patients with diabetes mellitus. They studied 78 patients type I diabetes mellitus (T1DM) and type 2 diabetes mellitus (T2DM). Among this group 37patients had chronic kidney disease.
The serum concentration of Ang-2 was higher in patients with chronic kidney disease (T1DM and T2DM), renal failure (T1DM), proteinuria and anemia (T2DM). Serum Ang-2 strongly associated with albuminuria (T1DM and T2DM), glomerular filtration rate (T1DM) and hemoglobin (T2DM). Obtained results demonstrate that serum levels of Ang-2 (but not Ang-1) are raised in patients with diabetic kidney disease and associated with markers of renal damage and anemia[22].

Another study by David et al., (2010) showed that: (i) plasma Ang-2 levels steadily increase with the progression of CKD. (ii) There is a significant inverse correlation between plasma Ang-2 and inulin-measured glomerular filtration rate (iGFR) in CKD stages $1-4$. (iii) The sudden loss of GFR after the unilateral nephrectomy in apparently healthy subjects is related to an increase in circulating plasma Ang-2[23].

The positive correlation with serum creatinine and the negative correlation with GFR suggest that increased Ang-2 may be associated with the development of renal impairment. Blood Ang-2 levels rise in line with the decline in renal function in type $2 \mathrm{DM}$ (David et al., 2012)[24] and CKD (Ogawa et al., 2013)[25], and this inverse correlation may predict longterm mortality in patients with CKD [26].

Two other studies reported that plasma Ang-2 levels were elevated in adults on hemodialysis (HD) or peritoneal dialysis (PD) compared with healthy controls (David et al., 2009\& David et al., 2012)[27] [24]. In one of these studies, plasma Ang-2 correlated with scoring for coronary and peripheral arterial disease [27]. In the other study, plasma Ang-2 correlated with serum cholesterol, high-sensitive C-reactive protein and osteoprotegerin and was an independent predictor of mortality [24].

In contrast to (Rukshana et al., 2013), plasma Ang-2 levels had no significant relation to age or gender, plasma Ang-2 levels were not significantly correlated with blood cholesterol, triglyceride, albumin, calcium, phosphate, parathyroid hormone, 25-hydroxyvitamin D or 
urinary albumin/creatinine levels in predialysis CKD or dialysis patients [28].

Chen et al., (2015) also observed no significant correlations were found between serum or urinary Ang-2 and age, BMI, DBP, SBP, HbA1c, FBS, HDL-ch, LDL-ch, serum total cholesterol, or serum triglyceride[16].

The differences between studies may reflect the different populations being studied, as well as variations in study design.

In our study, the positive correlation between plasma Ang-2 and CRP as an inflammatory marker agrees with that reported by Chang et al., (2013) whom found positive correlation between the plasma Ang-2 and hsCRP ( $\mathrm{r}=$ $0.114,95 \%$ CI $0.018-0.208, \mathrm{P}=0.020)$ [29].

Fiedler et al., (2006) identified Ang-2 as an autocrine regulator of endothelial cell inflammatory responses and Ang-2 acts as a switch of vascular responsiveness exerting a permissive role for the activities of proinflammatory cytokines[30][31]. Ang-2 serves the link between angiogenic and inflammatory pathway, Ang-2 signaling between cellular elements in renal fibrosis, including endothelial cells, pericytes, myofibroblasts, and macrophages[32].

In our study, the positive correlation between plasma Ang-2 and serum uric acid in all subjects and significant positive correlation between Plasma Ang-2 and serum uric acid in renal impairment group. This observation, also reported by (Rukshana et al., 2013), showed serum urate correlated with angiopoietin-2 levels in CKD and dialysis patients and addition of uric acid was able to induce rapid release of angiopoietin-2 from cultured endothelial cells[28].

Serum uric acid could directly induce the release of Ang-2 from human umbilical vein endothelial cell (HUVEC) with a corresponding decrease in mRNA abundance within the cell; consistent with prior reports that uric acid stimulates release of Weibel-Palade bodies [33].These effects are likely to be mediated by human uric acid transporter 1(Urat1) and Tolllike receptor 4 (Tlr4) [33], both of which were found to be expressed on endothelia. Studies using inhibitors specific for Urat1 (probenecid) [34]and Tlr4 (TAK-242) [35]would help to determine the specific role of these molecules in Ang-2 release from endothelia exposed to uric acid.

In our study, there is no significant correlation between plasma Ang-2 and micro-albuminuria or UACR as shown in table (16).

Our data are not in agreement with Chen et al., (2015) study showing increased urinary Ang-2 was positively associated with the degree of albuminuria, and these differences likely reflect the different populations being studied, age and state of disease as well as variations in study design[16].

In our study, there is no significant correlation between UACR and age, plasma Ang-2, serum total calcium, serum phosphorus $(\mathrm{p}>$ 0.05).There is significant positive correlation between UACR and MAP, serum creatinine, serum uric acid, CRP, serum total cholesterol, serum triglycerides, microalbuminuria . There is significant negative correlation between UACR and eGFR, Hb, serum albumin .

This agrees with a study done by KIM et al., (2005), they reported that the urinary ACR was found to be positively correlated with the duration of diabetes $(\mathrm{r}=0.246, \mathrm{P}=0.031)$, systolic blood pressure $(\mathrm{r}=0.171, \mathrm{P}=0.041)$, the creatinine level $(\mathrm{r}=0.391, \mathrm{P}=0.002)$, and to be negatively correlated with the creatinine clearance level $(\mathrm{r}=-0.286, \mathrm{P}=0.035)[36]$.

A large cross-sectional study has demonstrated an association between microalbuminuria and CRP [37].Festa et al., (2000) reported on 1,281 subjects from the Insulin Resistance Atherosclerosis Study. The study population contained patients with and without DM2. There was a positive association between microalbuminuria and elevated CRP and fibrinogen. The association was similar across gender and ethnic groups. The authors suggest that the association may arise from three possibilities: the independent development of atherosclerosis and microalbuminuria, the direct or indirect effect of cytokines on the glomerulus, or the presence of both from a common preexisting condition[37]. 
Fouad et al., demonstrated not only a higher level of serum uric acid in patients with ACR $\geq$ $30 \mathrm{mg} / \mathrm{g}$, but also a positive correlation with $\mathrm{ACR} \geq 30 \mathrm{mg} / \mathrm{g}$, and at a cutoff level of $>6.2$ $\mathrm{mg} / \mathrm{dl}$ identify the onset of early nephropathy in type 2 diabetic patients. Moreover serum uric acid level continues to raise with progression of overt diabetic nephropathy patients with ACR $\geq$ $300 \mathrm{mg} / \mathrm{g}$, and still positively correlated with $\mathrm{ACR} \geq 300 \mathrm{mg} / \mathrm{g}$ [38].

Biomarkers play an important role in the early detection of DN. Among them, the best known is microalbuminuria. At the same time, microalbuminuria represents a marker of the generalized endothelial dysfunction present in DM, linking renal involvement with cardiovascular and cerebral impairment [39].

Albuminuria or ACR has been considered for the last three decades as the golden standard diagnostic and prognostic biomarker for diabetic nephropathy onset and progression [40]. However, albuminuria lacks specificity for diagnosing disease progression when the urinary albumin excretion is $<300 \mathrm{mg} / 24 \mathrm{~h}$ and also lacks sensitivity since diabetic nephropathy can frequently progress without an increase in albumin excretion. Therefore, it does not serve as an accurate surrogate endpoint for the progression of diabetic kidney disease[41].

\section{CONCLUSION}

Angiopoietin-2 level is elevated in patients with diabetic nephropathy. Ang-2 levels steadily increases with the progression of albuminuria, suggesting its possible role as an early marker of microvascular complications. Ang-2 increases in parallel to poor glycemic control as reflected by its correlation with HbAlc.Ang-2 is related to CRP, this implies that elevated levels of this biomarker occur as a result of inflammation and vascular dysfunction as a part of atherosclerotic process.

\section{REFERENCES}

[1] Amann S"and Wolf G (2012) "Diabetic nephropathy,"Internist,vol. 53, no. 10, pp. 1195-1206.

[2] Menne J. and Haller H., (2011): "Diabetic nephropathy,'Internist,vol. 52, no.5, pp.495504.
[3] Hillege HL, Fidler V, Diercks GF, van Gilst WH, de Zeeuw D, et al. (2002): Urinary albumin excretion predicts cardiovascular and noncardiovascular mortality in general population. Circulation 106: 1777-1782.

[4] Gaede P, Vedel P, Larsen N, Jensen GV, Parving HH, et al. (2003): Multifactorial intervention and cardiovascular disease in patients with type 2 diabetes. $\mathrm{N}$ Engl J Med 348: 383-393.

[5] Stehouwer CD, Smulders YM (2006): Microalbuminuria and risk for cardiovascular disease: Analysis of potential mechanisms. J Am Soc Nephrol 17: 2106-2111.

[6] Libby P, Ridker PM, Maseri A (2002): Inflammation and atherosclerosis.Circulation 105: 1135-1143.

[7] Stenvinkel $\mathrm{P}$, Ketteler $\mathrm{M}$, Johnson RJ, Lindholm B, Pecoits-Filho R, et al. (2005): IL10, IL-6, and TNF-alpha: central factors in the altered cytokine network of uremia-the good, the bad, and the ugly. Kidney Int 67: 12161233.

[8]Futrakula N and Futrakul P (2017): Biomarker for early renal microvascular and diabetic kidney diseases, RENAL FAILURE, VOL. 39, NO. 1, 505-511.

[9]Andersen AR, Christiansen JS, Andersen JK et al., (1983): Diabetic nephropathy in type 1 (insulin dependent) diabetes: an epidemiological study. Diabetologia. 25:496501.

[10] Lane J. T (2004): "Microalbuminuria as a marker of cardiovascular and renal risk in type 2 diabetes mellitus: a temporal perspective," American Journal of Physiology-Renal Physiology, vol. 286, no. 3, pp. F442-F450.

[11] NarisaFutrakula and Prasit Futrakul (2017): Biomarker for early renal microvascular and diabetic kidney diseases, RENAL FAILURE, VOL. 39, NO. 1, 505-511.

[12]K/DOQI Clinical Practice Guidelines (2007): $\mathrm{K} / \mathrm{DOQI}$ clinical practice guidelines and clinical practice recommendations for diabetes and chronic kidney disease. Am J Kidney Dis; 49(Suppl 2): S12.

[13] RasulSazan, Marie Reiter, Aysegul Ilhan et al., (2011): Circulating angiopoietin-2 and soluble Tie-2 in type 2 diabetes mellitus: a crosssectional study, Cardiovascular Diabetology 10:55. 
[14] Svensson M, Nyström L, Schön S et al., (2006): Age at onset of childhood-onset type 1 diabetes and the development of end-stage renal disease: a nationwide population-based study. Diabetes Care; 29:538.

[15] Rizkalla B, Forbes JM, Cao Z et al., (2005): Temporal renal expression of angiogenic growth factors and their receptors in experimental diabetes: role of the reninangiotensin system. J Hypertens; 23:153-164.

[16] Chen S, Huiqing Li, Chun Zhang et al., (2014): Urinary Angiopoietin-2 Is Associated with Albuminuria in Patients with Type 2 Diabetes Mellitus, International Journal of Endocrinology Volume 2015, Article ID 163120, 7 pages.

[17] Lim HoongSern, Gregory YH Lip, Andrew D Blann et al., (2004): Angiopoietin-1 and angiopoietin-2 in diabetes mellitus: relationshipto VEGF, glycaemic control, endothelial damage/dysfunctionand atherosclerosis, Atherosclerosis 180, 113-118.

[18] Lip P L, Chatterjee S, Caine G J et al., (2004): Plasma vascular endothelial growth factor, angiopoietin-2, and soluble angiopoietin receptor tie-2 in diabetic retinopathy: effects of laser photocoagulation and angiotensin receptor blockade, Br J Ophthalmol ;88:15431546.

[19] Yamamoto Y, Kato I, Doi T, Yonekura H, Ohashi S, Takeuchi M, et al., (2007): Development and prevention of advanced diabetic nephropathy in RAGE-overexpressing mice. J Clin Invest. 2001;108:261-268.

[20] Okamoto T, Yamagishi S, Inagaki Y et al., (2002): Angiogenesis induced by advanced glycation end products and its prevention by cerivastatin. FASEB J;16:1928-30.

[21] Oh H, Takagi H, Suzuma K et al., (1999): Hypoxia and vascular endothelial growth factor selectively up-regulate angiopoietin-2 in Bovine microvascular endothelial cells. J Biol Chem; 274:15732- 9.

[22] Martynov SA, Shestakova MV, Kutyrina IM, et al., (2013): Role of circulating angiogenic factors in diabetic kidney disease, Vestn Ross Akad Med Nauk. 2013;(2):35-42.

[23] David S, Kumpers P, Lukasz A et al., (2010): Circulating angiopoietin-2 levels increase with progress of chronic kidney disease. Nephrol Dial Transplant 25: 2571-2576.

[24] David S, John SG, Jefferies HJ, Sigrist MK, Ku "mpers P, et al. (2012): Angiopoietin-2 levels predict mortality in CKD patients. Nephrol Dial Transplant 27: 1867-1872.

[25]Ogawa S., K. Nako, M. Okamura et al., (2013): "A decline in glomerular filtration rate rather than renal arterial stenotic lesions, per se,predicts cardiovascular-renal events in type 2 diabetic patients,"Circulation Journal, vol. 77, no. 11, pp. 2816-2822.

[26] Chang F-C, Lai T-S, Chiang C-K et al. (2013): Angiopoietin-2 Is Associated with Albuminuria and Microinflammation in Chronic Kidney Disease. PLoS ONE 8(3): e54668. doi:10.1371/journal.pone.0054668.

[27] David S, Ku "mpers P, Hellpap J, Horn R, Leitolf H, et al. (2009): Angiopoietin-2 and cardiovascular disease in dialysis and kidney transplantation. Am J Kidney Dis 53: 770-778.

[28]Rukshana C. Shroff1, Karen L. Price et al., (2013): Circulating Angiopoietin-2 Is a Marker for Early Cardiovascular Disease in Children on Chronic Dialysis.

[29] Chang F-C, Lai T-S, Chiang C-K et al., (2013): Angiopoietin-2 Is Associated with Albuminuria and Microinflammation in Chronic Kidney Disease. PLoS ONE 8(3): e54668. doi:10.1371/journal.pone.0054668.

[30] Chong AY, Caine GJ, Freestone B et al., (2004): Plasma angiopoietin-1, angiopoietin-2, and angiopoietin receptor tie-2 levels in congestive heart failure. J Am CollCardiol 43: 423-428.

[31] Fiedler U, Reiss Y, Scharpfenecker M, Grunow V, Koidl S, et al. (2006): Angiopoietin-2 sensitizes endothelial cells to TNF-alpha and has a crucial role in the induction of inflammation. Nat Med 12: 235-239

[32] Woolf AS, Gnudi L, Long DA et al., (2009): Roles of angiopoietins in kidney development and disease. J Am Soc Nephrol; 20:239-44.

[33]Kuo MC, Patschan D, Patschan S et al., (2008): Ischemia-induced exocytosis of Weibel-Palade bodies mobilizes stem cells. J Am Soc Nephrol 19: 2321-2330.

[34] Price KL, Sautin YY, Long DA et al., (2006): Human vascular smooth muscle cells express a urate transporter. J Am SocNephrol 17: 17911795.

[35] Matsunaga N, Tsuchimori N, Matsumoto T et al., (2011): TAK-242 (resatorvid), a smallmolecule inhibitor of Toll-like receptor (TLR) 4 signaling, binds selectively to TLR4 and interferes with interactions between TLR4 and 
its adaptor molecules. MolPharmacol 79: 3441.

[36] KIM NH, JEONG HH, JI A et al., (2005): Vascular endothelial growth factor (VEGF) and soluble VEGF receptor FLT-1 in diabetic nephropathy, Kidney International, Vol. 67 (2005), pp. 167-177.

[37] Festa A, D'Agonstino R, Howard G et al., (2000): Inflammation and microalbuminuria in nondiabetic and type 2 diabetic subjects: the Insulin Resistance Atherosclerosis Study. Kidney Int 58: 1703-1710.

[38] Fouad M, HodaFathy, AmalZidan (2006): Serum uric acid and its association with hypertension, early nephropathy and chronic kidney disease in type 2 diabetic patients, Original article, DOI: 10.5935/01012800.20160065 .
[39] Cristina Gluhovschi, Gheorghe Gluhovschi, Ligia Petrica et al., (2016): Urinary Biomarkers in the Assessment of Early Diabetic Nephropathy, Journal of Diabetes Research, Volume 2016 (2016), Article ID 4626125, 13 pages

[40] Wang C, Li C, Gong W, Lou T. (2013): New urinary biomarkers for diabetic kidney disease. Biomark Res.;1:9. doi: 10.1186/2050-7771-19. [PMC free article] [PubMed] [Cross Ref]

[41] Khalid Al-Rubeaan, Khalid Siddiqui, Mohammed A. Al-Ghonaim et al., (2017): Assessment of the diagnostic value of different biomarkers in relation to various stages of diabetic nephropathy in type 2 diabetic patients Published online 2017 Jun 2. doi: 10.1038/s41598-017-02421-9. 